On March 24th, 1899, he weighed seven stones $10 \frac{1}{2}$ pounds. He stated that he felt in good health, and that he could eat ordinary food. Shortly after this he became ill again with pain and romiting. He gradnally got worse and died at home, so far as we could learn, about six months after the operation. There was no necropsy.

Newcastle-on-Tyne.

\section{NEVUS VERRUCOSUS ASSOCIATED WITH CERTAIN ANOMALIES OF PIGMENT.}

\section{By H. TAYLOR, M.A. Cantab., M.A., M.D. Dub.}

THE marked manner in which the lesions are rigorously limited to the right side of the patient, their distribution in the track of certain cutaneous nerves, the alternation of deeply pigmented papillomata with merely the presence of pigment in the skin, and finally the merging of this pigmented condition into decolourised patches, make, I venture to think, this case of nævus verrucosus worth recording.

The patient is a lad, some 19 years of age, well nourished and in good health, with no history of syphilis or tubercle, who displays on his right breast a fairly extensive nævus verrucosus. Over the right pectoral region there is a dense crop of pigmented, non-hairy warts extending into the axilla and, though somewhat thinning out, half-way down the inner aspect of the right arm. At about the level of the nipples the warts reach the median line of the body, but they gradually disappear and are replaced by a line of reddish-brown pigment which is continued down to the umbilicus where again a few growths appear. (See Fig. 1.)

FIG 1.

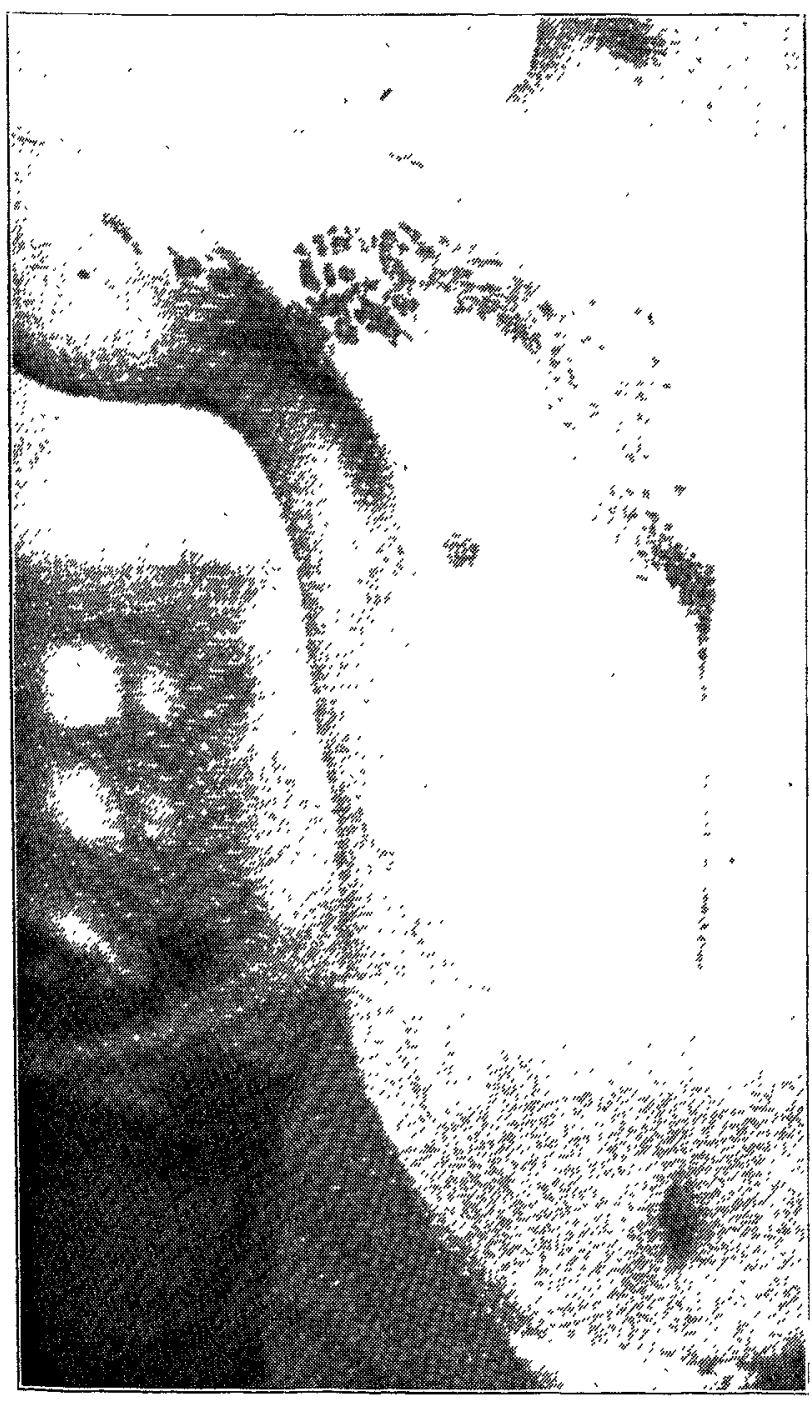

Crop of pigmented non-hairy warts.

From the umbilicus to the pubes another faint 'brown line can be traced, unaccompanied by any warts, but on the right side of the scrotum and penis some can be found and with then a few reddish scars, the site of previous ones which the patient states have "dropped off." Similar scars can be seen on the right side of the forehead, nose, and chin, the result of treatment with the actual cautery. Down the inner side of the right leg, from the groin to the inner malleolus, is another faint line of pigment which becomes more marked behind the ankle and is apparently merged into five or six oval-shaped, raised, colourless patches of a leathery consistence, placed along the inner edge of the right foot ("white moles" of Hutchinson?). (See Fig. 2.)

FrG. 2.

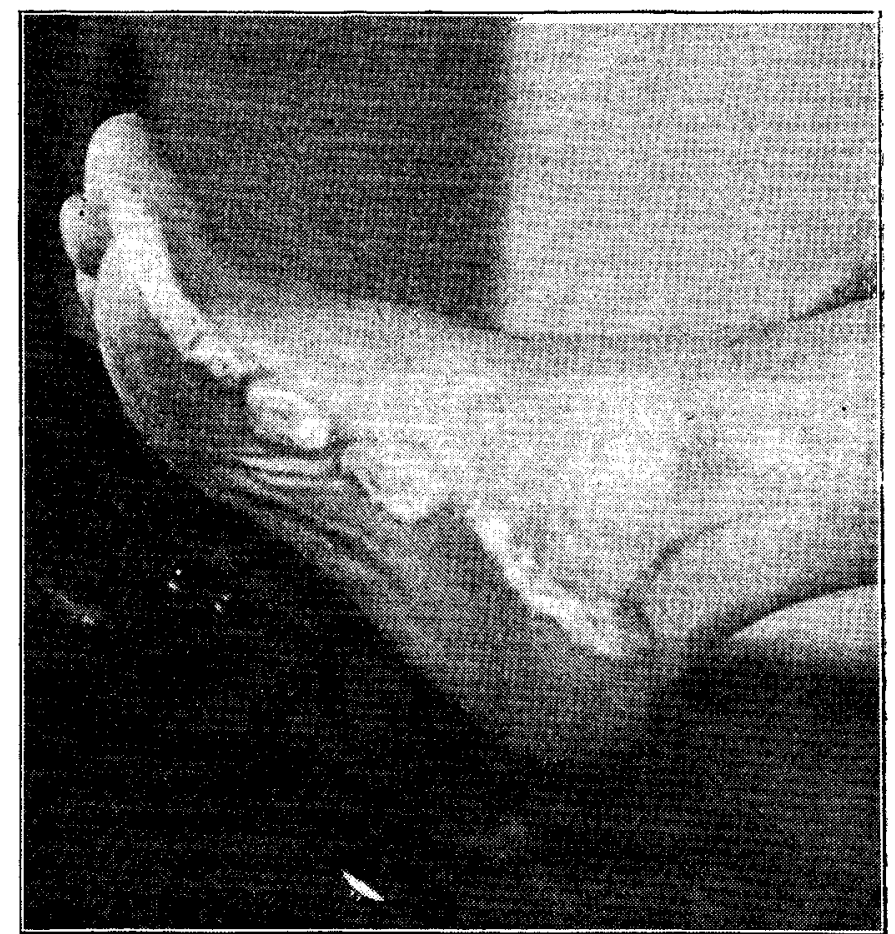

Nævus verrucosus associated with certain anomalies of pigment.

There are no skin lesions of any description on the left side of the patient; all are confined absolutely to the right. The patient asserts that he sweats more freely over the affected side and that the principal inconvenience which he labours under arises from this hyperidrosis, with-in a not too cleanly person-the inevitable decomposition of the sweat and the consequent chafing of contiguous parts. The condition is congenital and the various patches have grown only proportionately with the individual. There is no history of any of his relatives having been similarly affected.

The warty growths over the pectoral region are well illustrated in Plate 35 of Mracek's "Hand Atlas of Skin Diseases."

\section{A NEW METHOD OF BREAKING DOWN RECEN'T ADHESIONS.}

BY GEORGE W. ORD, L.R C.P. LOND., M.R.C.S. ENG.

To break down adhesions without an ancesthetic in either hospital or private practice is, owing to various causes, often a matter of necessity. 'The passive motion which follows the breaking-down, always a painful proceeding, frequently takes the form of fine-drawn and repeated agony. In private cases the surgeon's individual reputation will suffer if a stiff joint should result, and passive movements, owing to the pain they cause, lead in too many cases to latent resentment, an apprehensive dread of the practitioner's visit, and sometimes to an absolute refusal to undergo the torture. Our policy is, therefore, to be sure and brief in our manipulations and to avoid making passive movement the prolonged tussle between practitioner and patient, or between masseur and patient, which has so far seemed to be inevitable.

The method which I am about to describe consists in fixing the part above the stiff joint, by means of the surgeon's left hand, to the bed or the table, as the case may be, and then quickly flexing or causing movement in the joint. Adhesions in the wrists, the shoulders, and the knees we, I contend, break down without first putting the patient into a proper 